\section{Reply to Liccardi et al. Why Are Allergens Not Detected in Bronchoalveolar Lavage Fluid?}

Rueda $\mathrm{M}^{1}$, López-Matas $\mathrm{MA}^{2}$, Agustí $\mathrm{C}^{3}$, Lucena $\mathrm{C}^{3}$, Carnés $\mathrm{J}^{2}$, Valero $\mathrm{A}^{3,4}$

${ }^{1}$ Allergology Service, Hospital Quirónsalud Barcelona, Spain

${ }^{2} R \& D$ Allergy \& Immunology Unit, Laboratorios LETI S.L.U., Madrid, Spain

${ }^{3}$ Pneumology and Allergy Service, Hospital Clinic, Barcelona, Spain ${ }^{4}$ Institut d'Investigacions Biomèdiques August Pi i Sunyer (IDIBAPS), Centro de Investigaciones Biomédicas en Red de Enfermedades Respiratorias (CIBERES), Barcelona, Spain

J Investig Allergol Clin Immunol 2019; Vol. 29(6): 474 doi: $10.18176 /$ jiaci.0448

Key words: Lower respiratory airways. Mass spectrometry. Allergen. Bronchoalveolar lavage. Asthma.

Palabras clave: Vías aéreas inferiores. Espectrometría de masas. Alérgeno. Lavado broncoalveolar. Asma.

\section{To the Editor:}

We appreciate the interesting letter by Liccardi et al [1], which feeds and supports the discussion about the capacity of allergens to penetrate the lower airways. We also share the opinion that further studies are needed to explain the penetration of allergens, especially its correlation with induction of symptoms.

Regarding the presence of the allergen load in the environment, in Spain, fungi and grasses are seasonal allergens, while house dust mites are the major perennial allergen source and the most relevant cause of allergic rhinitis and allergic asthma [2]. With the objective of detecting temporary differences, we intentionally chose a perennial allergen (Der p 1) and seasonal allergens (Alt a 1 and Phl p 5). Other allergens may play a relevant role, although we consider these 3 allergens to be the most representative, based not only on seasonality and allergenicity, but also on their particularities as proteins. It is also important to highlight that massive sequencing by mass spectrometry revealed no allergens. While this technique has the capacity to identify any protein sequence present in the sample, no cat or dog allergens were found.

Furthermore, the main objective of the study was to evaluate the presence of allergens in the bronchoalveolar lavage fluid of patients without obstruction [3]. Bronchial pathophysiology in asthmatic patients may differ from that of other patients, and obstruction may hamper clearance of allergens. In an obstructed bronchus, some molecules could be hard to eliminate from the distal airway. In that case, the absence of antigens in the bronchioalveolar lavage fluid of patients with nonobstructive disease could be explained by this difference.

Up to $10 \%$ of patients with asthma develop respiratory symptoms after bronchoscopy. We currently perform bronchoscopy in asthmatic patients, although only in those who have difficult-to-control severe asthma or for research, which is subject to specific recommendations [4]. In light of the results of this study, we have a reasonable doubt about the distribution of allergens in the airways. As we state in our conclusions, we aim to solve this question in future studies on asthmatic patients.

\section{Funding}

The authors declare that no funding was received for the preparation of this letter.

\section{Conflicts of Interest}

MA López-Matas and J Carnés are employees of Laboratorios LETI S.L.U. The remaining authors have no conflicts of interest.

\section{References}

1. Liccardi G, Calzetta L, Milanese M, Bilò MB, Rogliani P. Why are allergens not detected in the bronchoalveolar lavage fluid of patients undergoing fiberoptic bronchoscopy? Possible explanations. J Investig Allergol Clin Immunol. 2019;29:472-3.

2. Calderon MA: Respiratory allergy caused by house dust mites: What do we really know? J Allergy Clin Immunol. 2015;136:38-48.

3. Rueda M, Lopez-Matas MA, Agusti C, Lucena C, Carnes J, Valero A. Allergens are not detected in the bronchoalveolar lavage fluid of patients undergoing fiberoptic bronchoscopy. J Investig Allergol Clin Immunol. 2019;29:148-50.

4. Du Rand IA, Blaikley J, Booton R, Chaudhuri N, Gupta V, Khalid S, et al. British Thoracic Society guideline for diagnostic flexible bronchoscopy in adults: accredited by NICE. Thorax. 2013;68 Suppl 1:i1-i44.

- Manuscript received July 25, 2019; accepted for publication September 4, 2019.

\section{- Jerónimo Carnés}

R\&D Allergy \& Immunology Unit

Laboratorios LETI, S.L.U.

Calle del Sol $n^{\circ} 5$

28760 Tres Cantos (Madrid), Spain

E-mail: jcarnes@leti.com 